\title{
Existential Driving Forces to Work after Retirement: The Example of Physicians' Mentoring'
}

I Mattias Bengtsson ${ }^{2}$

Associate Professor, University of Gothenburg, Department of Sociology and Work Science, Sweden

I Marita Flisbäck

Professor, University of Borais, Department of Work Life and Social Welfare, Sweden

\begin{abstract}
The article addresses physicians who work as group supervisors or mentors in a training program after having formally retired. The driving forces to continue to work are analyzed in terms of the development of existential meaning of work at a particular stage of the life cycle. We argue that a deeper understanding of the existential driving forces, that both cause physicians to accept post-retirement mentoring tasks and that is awakened and developed in this specific work, would contribute to a deeper understanding of why individuals continue working into old age. However, in political discussions of an extended working life, similar aspects tend to be disregarded. Understanding the existential driving forces that cause an individual to continue working after retirement may be crucial to comprehending how we can take advantage of the resources of the older workforce and, thus, realize human potential at a later stage of the life cycle.
\end{abstract}

\section{KEYWORDS}

Existential driving forces / existential imperative / extended working life / generativity / mentoring / physician / recognition

\section{Introduction}

I think it's a meaningful existence ... when I feel I have good relationships with other people who give me joy and warmth back, then I think it's a meaningful life. And, when I feel I can use some of what I have in me, in my profession. / ... / Use my abilities. Well, using all the experience I've had in my professional life, over the years ... that it somehow exists, even as I get older.

n Europe, politicians have emphasized that more people need to work at higher ages to ensure the general welfare level and supply of skills (Eurostat 2018). Whether a work career is extended has been shown to be a matter of health, financial incentives, the retirement decisions of spouses or friends, as well as social factors such as gender, class and institutionalized norms (Berglund et al. 2017; Kadefors et al. 2016, 2018; Kosonen et al. 2021; Nilsson et al. 2011; Solem et al. 2016). Moreover, work-related factors as work demands, job autonomy, social support, learning and development

\footnotetext{
${ }^{1}$ You can find this text and its DOI at https://tidsskrift.dk/njwls/index.

${ }^{2}$ Equal co-authors. Corresponding author: mattias.bengtsson@gu.se.
} 
opportunities, challenging work, organizational retirement culture, recognition and respect, and mentoring opportunities have been shown to influence older workers' continued workforce participation (Carr et al. 2016; Chen \& Gardiner 2019; Dal Bianco et al. 2015; Thorsen et al. 2012; Van Solinge \& Henkens 2014). Conversely, there are some substantial demand-side barriers. Discrimination, expressed by employers' negative attitude towards an older workforce, affects the possibility of an extended working life (see, e.g., Kadefors \& Johansson Hanse 2012).

Studies emphasize how well-executed human resources work, involving such as joint planning for a lifelong career and strategies stressing recognition and respect, can motivate older employees to postpone retirement (cf. Armstrong-Stassen 2008; Kooij et al. 2008). However, an interview study of line managers and HR partners in the Swedish healthcare sector show that despite having positive attitudes toward utilizing older employees' skills, practical circumstances, such as lack of time due to high workload, make strategic planning for age-management strategies very difficult (Jonsson et al. 2020). The fact that age management has a lower priority in personnel work is an example of how ageism, that is, that the competences of the older workforce are devalued, is expressed at a practical level.

However, according to Biggs (2014), another main aspect of ageism is overlooking that older people, in comparison with the middle-aged, may find other aspects than work meaningful in their lives. In old age, Biggs points out, work is attributed a different - or lesser - importance. Thus, to understand the driving forces underlying extended work careers, we argue that we need to focus on the content of work. A meta-analysis of age and work-related motives showed that intrinsic motives were stronger among older than among younger employees (Kooij et al. 2011). For example, Mor-Barak (1995) showed that jobs that enable the transfer of knowledge and experiences to younger generations is a primary source of work meaning or work incentive among older employees (cf. Calo 2005; Deller et al. 2009).

In Sweden, it is professionals with higher status and longer education, such as physicians, who are most likely to work after the age of 65 (Kadefors et al. 2018). ${ }^{1}$ The question is why? Is it all about a strong professional identity, the salary, status, working conditions and the opportunity to work on a smaller scale, or the desire to continue performing an important task?

The article will address the question by focusing older physicians who work as group supervisors in a training program for healthcare employees who obtained a license to practice medicine from a university outside Sweden. ${ }^{2}$ Since the question of an extended working life is related to both generally lower valuation of older employees and difficulties in creating sufficiently attractive working conditions for this group, the program serves as an example of tasks that could be meaningful both to the organization and to the individual in a later stage of the (working) life cycle.

There is an important methodological point in studying older physicians, which is a privileged group in the sense that they do not in general have to continue to work for financial reasons. By studying this specific group, we can understand more fully the intrinsic work-related motives for continued work after retirement. We do this by offering a complementary perspective on underemphasized existential driving forces that may become more prominent at a particular stage of the life cycle for older people (no matter what types of professions or class positions). Moreover, we argue that this is an important equality issue. Individuals in the same life phase are expected to have similar 
types of needs (cf. Biggs 2014; Erikson 1950) and, thus, it is reasonable to offer less privileged workers the possibility to satisfy work-related existential meaning.

The initial quote indicates that the reasons for supervising at the training program seem to relate to a specific context with new challenges and where competences from a long professional life are recognized and transferred, and in this way, the task is a question of existential meaning and realization of human potential. By combining an existential sociology approach with the concepts generativity and recognition, we argue that a deeper understanding of existential driving forces would contribute to new angles on why individuals continue to work into old age. Before deepening our analysis of three important driving forces that we have discerned; to get existential recognition, to find a meaningful context, and to perform tasks pointing to the future, we will present the sections on background, theoretical perspectives, and data and method.

\section{Background: A case of mentoring}

Mentoring is exercised either informally or within the framework of a formal mentoring program and usually understood as a two-person relationship (Doerwald et al. 2015). However, we have chosen to see the physicians' group supervision as a form of mentoring. We have shown how older physicians possess a specific competence - 'occupational-life competence' - where they have developed an ability to handle uncertainty and contingency in the work situation as a whole (Bengtsson \& Flisbäck 2019). The competence is an existential proficiency, based on experiences from both professional life and life in general, and which seems to be particularly important in the mentoring practice.

From an individual perspective, mentoring can facilitate continued work after retirement, without paid work competing with aspects of life such as family and personal development. Moreover, this occurs at a specific life phase when the intrinsic value of work may be of particular importance to the individual. From a societal and organizational perspective, mentoring can help to make the older workforce's accumulated experience and knowledge visible, and to transfer and retain this in the organization and in working life as a whole (Doerwald et al. 2015; Mykletun \& Furunes 2011).

Research has pointed out how organizations that appreciate older employees' experiences and abilities are able to see that these may have special - and sometimes even better - competencies than their younger colleagues. These skills may be very useful in the process of transferring knowledge to younger colleagues (Mykletun \& Furunes 2011). From the perspective of the older individual, such a transfer of knowledge may also be experienced as existentially enriching.

\section{Theoretical framework}

\section{Existential sociology approach}

In this article, the driving forces to continue working after retirement, as a supervisor/ mentor, is analyzed in terms of the development of existential meaning of work at a particular stage of the life cycle. Understanding questions as existential mean that they touch on the meaning of life, one's own and others' life deeds, ethical issues, and man's allotted 
time. An existential sociology approach focus on how individuals, under the influence of the inexorable condition of finitude, create meaning in multifaceted ways (Bengtsson $\&$ Flisbäck 2021). The temporal dimensions of life are emphasized, as meaning is always given to us through time. We live with our past, while we in the present also must relate to a possible future and the fact that our lives are finite (cf. Heidegger 1927/2013). Thus, when we are reminded of life's finitude, such as at old age or when we withdraw from the obligations of full-time employment into retirement, it may become increasingly important that we largely engage in activities which are perceived to be meaningful.

To explain why intrinsic factors of work may increase in importance with aging (see, e.g., Mor-Barak 1995; Kooij et al. 2011), the concept 'existential imperative' is useful. With this concept, Jackson (2005) attempted to capture how meaning is created at various turning points in life, for example, when professional life is about to end. Existential imperatives can be interpreted as an enhanced existential mood that emerges when something in the environment changes. Here, one can perceive existence as more open than before, but also more uncertain. This can lead to reflection on what gives life meaning, and here meaninglessness and incomprehension are equally likely outcomes as the feeling of having found a new meaningful direction in life.

In Jackson's view, a main aspect of existential imperatives is their potential to change the meaning and quality of life. When everyday routines are broken, people frequently hope that the future will be better than the present. This can have real consequences and lead to actual change. In this way, a new everyday life is possible. However, as Jackson (2011) emphasized, such change always takes place within social structures, which he described using the phrase 'life within limits'. If aging or retirement thus constitutes an existential imperative where new wishes have grown strong concerning what we want to realize regarding the existential meaning of work, then the possibility of this is limited, for example, by professional and class conditions. In the actual case, these conditions are very favorable for physicians.

\section{Generativity and recognition}

Research on older people's positions as mentors is often based on Erik H. Erikson's psychosocial development model where individuals undergo eight stages in the life cycle, from infancy to old age. A psychosocial crisis precedes each stage, and for our analysis, the seventh stage is of particular interest; it concerns adulthood and is dominated by the crisis 'generativity versus stagnation'. Generativity refers to individuals shifting their focus from their own interests to 'the concern in establishing and guiding the next generation' (Erikson 1950, p. 267). Erikson and Erikson (1997, p. 67, emphasis in original) described this as a new 'virtue' with a 'widening commitment to take care of the persons, the products, and the ideas one has learned to care for'. The opposite is to stagnate in a one-sided interest in one's own needs, with the risk of standing outside the meaning context created in common social practices and stories.

Generativity develops throughout adulthood, but in the eighth stage, the individual can also achieve 'ego integrity'. This refers to a form of existential contemplation in which the individual can shape a whole based on, or an integration of, his or her life experiences, thereby achieving a basic acceptance of life as it has come to develop (Erikson et al. 1986).

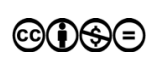


Alongside the elevated existential awareness that emerges through the aging process, existential meaning seems to be constructed or become more prominent in different situations along the life path, not least in connection with the approaching conclusion of professional life (cf. Jonsson 2000; Bengtsson \& Flisbäck 2021). However, it is not only generativity that is accentuated with aging and retirement. Studies indicate that the gratitude received in the retirement process, for example, via farewell ceremonies, may act as recognition of the individual's achievements from a long professional life (cf. Bengtsson et al. 2017). Likewise, recognition in post-retirement employment does not only affect well-being in the present, but also the person's view of the past as well as the future. This follows from that recognition influences the individual's perception of that extensive work investments have been shown to be of value for other people and, thus, meaningful. This affects the experience of the present as meaningful and, thus, that the future can be met with confidence. Consequently, in line with an existential sociology approach, we stress that recognition needs to be connected to the temporal dimensions of life.

According to Honneth (2003), individuals' struggle for recognition is a main aspect of social life. Our profession is fundamental to how we think about ourselves and shape our self-image. Thus, if colleagues recognize our professional knowledge, it will make a significant contribution to experiencing our value as social beings (Sayer 2005). On the contrary, misrecognition threatens our well-being (Honneth 2003), as well as the opportunity to shape meaningful work that is a crucial aspect of dignity in work (Hodson 2001). As emphasized by Bolton (2007), the quest for recognition concerns more than being appreciated by managers or employees. It is also a matter of dignity with respect to one's autonomy and skills, as are reasonable pay and fair working conditions (cf. Sayer 2005).

In their struggles for recognition, human beings are particularly anxious to be recognized for the aspects that they consider being fundamental in their identities (Honneth 2003). The recognition we receive from others must have a resonance in what we believe make our own lives and efforts meaningful. A key existential aspect here is that it is through the recognition of others that we see both our value and our place in a larger life context. Here, both old age and retirement constitute critical situations since some people feel being undesirable in working life and society in general. It is therefore important, as we do in the present study, to highlight situations in working life that can promote recognition and counteract disrespect and misrecognition.

\section{Data and method}

\section{Background of the study and sample}

The present study began when the University of Gothenburg was asked by the Region Västra Götaland in Sweden to study a training program for foreign-trained healthcare personnel who are now working in Sweden. It was up to the researchers to decide which aspects to explore.

The program aims to supplement the participants' knowledge and experience by increasing their familiarity with the Swedish healthcare system as well as by deepening their knowledge of professional communication and the Swedish language. The training 
takes place during paid working hours, once a week for a period of 34 weeks. One main part of the program is group supervision, which the foreign-trained physicians are required to attend 3 hours a week. Retired healthcare personnel with many years of experience are recruited as group supervisors. Having previously studied existential meaning making after retirement, we found the older physicians assignment as supervisors particularly interesting to study.

The study began with that the program administrator provided us with contact information for the supervisors, who had already been informed that they would be asked to participate in an interview study. Thereafter, we distributed written requests for personal interviews that included information about the research project's funding, purpose, design and ethical principles. All 15 persons who were asked agreed to participate in the study. Most interviews lasted 1 and a half hours to 2 hours.

In qualitative interview studies, the number of interviews always constitute benchmarks, which cannot be determined in advance. A main selection criterion is that the empirical data should have sufficient width and complexity in relation to the research questions. In other words, the selection is about gathering the type of data needed for real knowledge development (Charmaz 2014). A limitation of our study was that the number of interviewed physicians were restricted to 15 in total. More interviews, and with other professional groups, had probably further developed and confirmed our analytical categories. In other words, it would have been advantageous if we should have had the opportunity to discuss which categories that seem to be more general among health care personnel in post-retirement supervisory positions.

The program conducts similar training with other health care professions. Therefore, we have also interviewed a nurse who is a group supervisor. Moreover, to get a broader perspective, we also conducted a joint interview with the current and former program manager, and studied a selection of the participants' evaluations of the program.

Of the interviewed physicians, nine are women and six are men; they were born between 1941 and 1953. Their respective family situations differ in terms of marital status, whether the person is a parent, or has grandchildren, etc. The interviewees have different qualifications and professional skills. They have experiences from management, foreign work and previous supervisory positions. Some have several vocational training courses, others a doctoral degree. They possess knowledge and experience from different specialties: general medicine, pediatric medicine, child neurology, geriatrics, gynecology, internal medicine, cardiology and psychiatry. They also differ in how long they have been supervisors in the program; one has been program manager.

\section{Data analysis}

This article has focused neither on finding differences and contradictions between and within different interviewees' life stories, nor on highlighting gender and age differences. Rather, we have devoted ourselves to develop categories that mark key aspects of driving forces to continue working after retirement even when you no longer have to work due to financial constraints.

With regard to principles for data processing and analysis, we were guided by the constructivist grounded theory approach. Thus, the analysis has been empirically grounded, involving a coding process that goes from empirical indicators to conceptual 
abstractions, to facilitate further theory integration (Charmaz 2014; cf. Holton 2007). According to this method, different types of coding in subsequent steps is part of an 'emergent process' that enables discovery of new aspects, by continually asking new questions to the data. During the entire coding process, we wrote extensive 'memos', which formed the core of the ongoing analysis of the data and helped us to explore ideas about the codes (Charmaz 2014). In this way, the abstraction level gradually increased, and subsequently resulted in the development of categories. However, besides the empirically grounded analysis, theoretical perspectives and concepts also guided the data analysis. A starting point for the research project was an existential sociology approach, while the concepts of generativity and recognition were added in a later stage of analysis. This eventually led to the development of three main theoretical categories. These highlight main aspects of existential driving forces at a particular stage of the life cycle: 'A specific recognition at a specific time in the life cycle', 'A specific context at a specific time in the professional life cycle' and 'A specific task at a specific time in the life cycle'.

\section{Results}

Studies of clinical supervision have pointed out that factors such as strong professional identity, devotion, experience and interest in and responsibility for younger colleagues are important to being a good supervisor (von Below et al. 2015). Our study also testifies to the importance of similar engagement and deep anchoring in the professional role, and what was previously referred to as occupational-life competence (Bengtsson \& Flisbäck 2019).

Supervision seems to benefit from the supervisor's wisdom and ability to utilize his or her own experiences to stimulate conversations about, for example, severe patient cases, reported medical mistakes, and disrespect on the part of colleagues or patients. This requires experiences from which examples can be retrieved, as well as having the courage - and the modesty - to dare to refer to events one is less proud of. Here, it may help that the older employees - in whole or in part - have put their professional careers behind them and are no longer competing with the younger physicians for recognition, power and resources in working life. Beyond this, it is essential that the supervisors have a genuine interest in listening to younger colleagues' experiences and putting these colleagues' thoughts in the forefront, an interest that may be caused by the supervisors being at a late stage in their professional life cycle (cf. Calo 2005; Mor-Barak 1995).

Research has shown that clinical supervision offers little merit value, short of time and space, and limited financial compensation (von Below et al. 2018). Likewise, neither the career nor the extra income provided by supervision towards the end of their professional life cycles seems to be a driving force when the physicians reflect on their reasons for choosing supervision.

My career is behind me. / ... / God, I'm 66 years old. I have no career ambitions ... I want to do what I think is fun to do now. / ... / If I wanted to make money, I'd work as a 'freelance physician' for a week or a month. I'd earn a lot more money, although of course I have a great salary. / ... / But if only money is involved, then I'd do something completely different. 
... it would not have been so cool to work as a bricklayer a few hours a week / ... / No more than for the money. But now you do this [group supervising] because it's fun and in terms of money, of course it's satisfying when you get them, but it's not the primary thing. No.

Physicians belong to one of the most highly paid professions in Sweden (Brante et al. 2015); they also enjoy great financial security during old age. In addition, lucrative positions can be offered to a retired physician, which one interviewee expresses above, though he declines them in favor of the stimulus provided by being a supervisor. Another interviewee explains that the task is 'a meaningful way to phase out of professional life' and, in a similar way, a third interviewee says that the role as supervisor has served as 'a winding down of social contacts' she has had throughout her professional life. In the following pages, we will look more closely at these aspects of the desire, meaning and enriching social relations of work, and discuss how the work of being a supervisor can be particularly important in a specific phase of both life and the professional life cycle.

\section{A specific recognition at a specific time in the life cycle}

When an individual retires, there may be a desire for recognition for one's efforts and time investments in professional life. In Bengtsson's et al. (2017) study of individuals' experiences of the retirement process, they discover that one precondition for perceiving the end-stage of professional life as satisfactory was that the organization 'managed', in a dignified manner, the contribution the individual thought he or she had made. In the present study, the older physicians describe how professional life has repeatedly demanded great sacrifices. For example, one interviewee describes an experience of having 'given his life' for his profession, at the expense of activities in other life spheres.

It was the most important thing, and it had to take the amount of time it took. There was no talk of going home half past five and picking up the children from kindergarten. / ... / You were enamored [of the work] and thought it had to go first.

In the transition into life as a pensioner, the sacrifices of the profession seem to have shaped a longing for gratitude for the life-long investment one has made. But, as said by one interviewee, there is a problem associated with being fulfilled by one's work - being a 'real enthusiast' - because the work invested in an organization may entail the risk of being invisible.

It's not like it [the organization] has run by itself, there's been a lot of lubrication ... Which has given me something, but has also taken things. Cost me. It has cost me a lot of energy.

If the desire for recognition for one's commitment and professional skills is not fulfilled when the retirement approaches, this could have a negative effect on older employees' intentions to extend their work careers. In our study, one interviewee describes how her manager downplayed the importance of her efforts by neglecting to pay attention to her retirement, the day she would leave an organization she had belonged to for almost four decades. 
Because he [the manager] said this: 'Now you're leaving the clinic. And we don't make a big deal of that, right?' 'No', I said, 'we don't. I did say ... And then I felt, 'Idiot!' I won't say it and I can't say it. But I'm probably even a little sorry for it ... Actually. / ... / I still think that I've contributed. I've been working in the healthcare sector since 1979, and 'we don't make that big deal of it'!

The disrespect or misrecognition shown by the manager is particularly marked in light of the fact that the interviewee is about to leave her professional life. Lack of recognition during the retirement process may create a feeling that the efforts one has made throughout one's professional life are invisible (cf. Bengtsson et al. 2017). Here, however, the group supervision position seems to offer quite the opposite: The young physicians' appreciation is an important source of recognition. What the interviewee lacked from her manager, she now receives from those she supervises.

I got a wonderful silk scarf. I'd never bought anything that expensive myself. From one group ... I think of them all the time when, when I pick it up, I think, 'Oh, yes it was them!' ... And when a Muslim man bought me a bottle of wine, that wasn't that bad either. He said, 'I don't drink myself, but I understand you like wine'. So it's been great fun!

Getting comparable appreciation at the end of one's professional life, as the interviewee describes above, makes the supervisory position worthwhile. It expresses that, despite rising age and with a looser anchoring in working life, one still has a value. Just the very fact of being in demand at the end of one's professional life can be seen as a benefit in the form of recognition.

I'm very happy and grateful that one are asking for me at all, because I think I have experiences that could be useful.

It provides a positive feeling and that one still somehow counts.

An experience of being in demand or receiving appreciation from peers is essential to well-being and satisfaction in work and life overall (Sayer 2005). Furthermore, the supervisory position offers another form of recognition than direct recognition from peers. When preparing the pedagogical activity, the physicians may discover that they have competencies that can be shared and, thus, have a value. One interviewee talks about how the knowledge and experience he has gathered throughout professional life become explicit (even for himself) when they are conveyed to participants in the program.

Then I usually reflect on, think: 'What should we talk about then?' So that you have some things like this, that we're going to talk about ... And then you have to structure yourself a little bit and I think it's fun too, before. / ... / And in it you discover that, well: 'My knowledge isn't so bad anyway', when you do it like that.

Human beings wish to be recognized for the aspects that they consider is fundamental in their identities (Honneth 2003). As our profession is central for shaping our selfimage, recognition of our professional knowledge is essential to satisfaction in everyday 
life. Moreover, another central aspect of recognition is that the knowledge one possesses is made visible. It is interesting that the recognition of professional knowledge the interviewee tells us about does not only originate in the supervision activity. Rather, it concerns the question of how different forms of knowledge may emerge as valuable competence when preparing the pedagogical activities of the mentoring role.

Regardless of whether knowledge is made visible in interaction with the program participants or when preparing the pedagogical activity, the supervisors become aware of - and thus recognized for - their professional knowledge. This act of recognition testifies that long-term professional investments that generated this knowledge have been meaningful because these are seen to be of value for others.

According to Erikson (2000), in the later part of the life cycle, a desire to summarize one's life for someone else may appear, following the existential desire to form a whole out of one's different life experiences. It is reasonable to imagine that a similar desire even may occur in the later part of the professional life cycle. When experiences are summarized, and competence is made visible in the act of supervision, the older physicians also hand over a central part of their own life. In this way, the recognition is existential. Similarly, the satisfaction of the organization requesting the competence implies an existential aspect, as the individual may experience an opportunity to make an impression and leave traces.

As long as I'm being asked, it's quite satisfying, because then it's a way to live on.

When older employees experience that organizations require their skills, a feeling may occur of being part of a larger context, of an activity that continues, and in this way their own lives carry on. Such existential recognition is also received in encounters with participants in the program. One interviewee depicts this in terms of winning participants' confidence.

You get confidence in return, I think this is an important thing ... So they entrust things to you. There were tough things for a couple of them who'd gone through things this year.

And then you become... Yes, then you become someone.

Winning others' confidence and trust can be existentially meaningful, especially at the end of the professional life cycle. In this way, the interviewees are recognized for more than their profession: They are also recognized as a specific person. In other words, at a specific time in life, supervisors are not only seen for what they know, but also appreciated for what they have been, and the special skills they have as human beings.

\section{A specific context at a specific time in the professional life cycle}

Hitherto, we have seen how a driving force for taking the position concerns the older physicians being recognized for their skills and professional experience, but also for being the individuals they are. Recognition can come from the organization, the program participants - that is, a new generation of physicians - or from the process of preparing the pedagogical activity, during which the physicians may discover that they have competencies they can share.

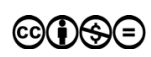


Recognition, thus, can be obtained through the honor of getting the position or the dignity that the practice itself offers (cf. Bolton 2007). If the retirement process is regarded as a phase in which the individual is - at least partly - decoupled from one of life's central contexts, then the supervision process can entail entering a new context.

The fact that professional life does not have to end even though one has formally retired is a main theme in the interviews. For example, one interviewee retired at the age of 66 . However, afterwards he has had both research positions and worked in the private business community. After a few years, he was asked to supervise at the program. He describes how several friends and acquaintances have continued to work in similar ways.

... there are many of my friends who still work ... So I'm in that kind of environment.

The interviewee claims to be in a social environment where it is common to work after retirement. Most people in his surroundings are also, like himself, highly educated and highly demanded in the labor market. However, whether an individual continues in or exits working life is not only a question of social influence or greater access to employment. Nor is it a question solely of health and economic conditions. It also concerns the individual's existential driving forces. New experiences and the passage of time may change, though, the content of these driving forces. An initial aversion to life as a pensioner may, after a while, lead to acceptance or the emergence of new meaning in life. However, Bengtsson et al. (2017) show how the longing to return to working life could grow strong a few months after retirement. Similarly, in the present study one interviewee talks about how he retired at the age of 65 , but after some time regretted the decision, believing he should at least have continued to work part-time. He describes how he regretted leaving the former working life context in which an important aspect of himself was confirmed: his professional identity. His longing to return to his former work became apparent a few weeks after retirement. When he later was offered a position supervising at the program, this new context was connected with his professional identity; it was a place where his knowledge could be transferred and his skills recognized.

Now it feels more ... not like a career step, but ... Well, it's fun that I can use that knowledge and the ... Well, in this context the great experience I have. It's fun!

Like the other physicians, advancing his career is not the driving force causing the interviewee quoted above to choose to supervise. Instead, group supervision seems to be a context that gives particular satisfaction at a specific point in time in life. Between employment's full-time obligations and a complete exit from working life, group supervision serves as a place where previous knowledge is utilized and interwoven. In the act of supervision, the interviewees take with them something from the past, which one interviewee expresses in the following way.

... is incredibly good, incredibly good because I can pick up the threads from different places.

On the way into one's new existence as a retiree, the supervisory position connects one's previous occupational activities and previous professional identity with a new space, in 
which opportunities are given to meet both older and younger colleagues. At a specific phase in the professional life cycle, the supervisory position offers the interviewees a special context, which both points back to the past and presents new challenges. For example, one meets older colleagues from earlier assignments and acquires new colleagues with whom experiences from the supervisory position can be exchanged.

I think it's so much fun, just to be in this building [where the programme takes place]. I mean, today I met [name] who I know from other earlier investigation assignments and things. In here are two of my, who I supervise at the addiction clinic, they're taking a course in forensic psychiatry, and you always meet lots of people.

Meeting fine colleagues from among the group supervisors. We can laugh and joke together and have good conversations when we talk about what we've been discussing today, what we've done and so on.

Furthermore, one does not only gain new colleagues and knowledge in the meetings that take place with the other supervisors, but also in encounters with the program participants. In other words, it is not only the young physicians' horizon of knowledge that is broadened during the group interactions, but also the older physicians'. In the supervised learning processes, the profession's difficult and meaningful aspects are explored, which also results in supervisors learning from program participants (cf. Doerwald et al. 2015).

I learn new things from the participants. Because they have very different backgrounds and I think that's exciting.

PLUS [the programme] is very important to me. / ... / I believe I learn more than anyone else, than my colleagues here.

The specific context of group supervising at the program provides an opportunity for an exchange between older and younger physicians. Here it is interesting that both groups are in a transition phase: one is moving out of working life, while the other is moving in. Both groups could reasonably be said to be in existential imperatives where meaning is intensified, constructed and given new signification (cf. Jackson 2005). Perhaps this benefits the task of mentoring, where knowledge is to be transferred to, but also is problematized by, a new generation of physicians.

We have seen how the group supervision can offer a context in which competence from the past becomes explicit, linked together, and recognized in a new way. At the same time, this new context and, not least, encounters with the foreign-trained physicians provide an opportunity for the older physicians to shift their own knowledge horizon. For one interviewee, as a pensioner, the position meant being restored in a new context of existential meaning.

I wanted to be in this context. A context that was linked to the job and job identity. And the things I've been very good at and think have been fun, which doesn't need to be talking with patients or performing surgery. 
The interviewee explains how he, early on as a younger physician, found surgery the most challenging of his work tasks. The ability to deal with lives that were hanging in the balance gave him great satisfaction. However, after a while, that satisfaction faded. Instead, communication with patients turned out to be the greatest challenge. Gaining trust and 'solving difficulties in talks' between himself and the patient were particularly meaningful tasks. They confirmed the interviewee's professional communication ability. However, in the latter part of the professional life cycle, supervision - like that taking place at the program - offers particular satisfaction. At the age of 74 , this work seems to offer a specific form of meaning in life.

\section{A specific task at a specific time in the life cycle}

What seems to attract the older physicians to continue working is that they do not continue in the same way as before. They have found a new context, also offering new kinds of tasks, which are particularly meaningful in this life phase. The question is why?

Using the concept of existential imperative, Jackson (2005) attempted to capture how issues of the quality of life and meaning of life can be particularly prominent during life's transitions and turning points. If questions about the meaning of life become particularly tangible when individuals are about to exit working life, then it is reasonable to imagine that the tasks they choose to perform during this phase must be perceived as existentially meaningful. But it is not just this exit that seems to have given rise to an existential imperative for the physicians interviewed. Even the experience of an aging self, the aging of one's social surroundings, and the fact that the body has become more vulnerable seem to constitute an existential imperative. When one interviewee describes his desire to be more involved in supervision, he stresses that one must be humble concerning the increasingly frail health that the aging brings and, therefore, how long it is possible to perform similar tasks.

In the first place, of course, I hope that I and the people around me can be healthy. It's not given when you're 66 years old. There are many friends who disappear, who get sick and die. So it ... There you have to be quite humble.

Being a physician means having a profession in which the vulnerability of life is ubiquitous. Despite this knowledge, a noticeable insight has nevertheless emerged concerning the delimited nature of life in both time and space.

... when you reach this age so ... I was at a funeral last ... now last Saturday, a good friend who had died. You can die at any age, but there is greater risk when you get to our age ...

The increased presence of death has meant that time and life plans must adopt a provisional and 'humble' form. As a consequence, it has become increasingly important to decide which issues one should devote one's time to. One interviewee, who has worked full-time throughout her professional career, describes her plans to reduce her work efforts the coming year. These reflections are mirrored in the experience of her husband passing away a few years ago, on the one hand, and her decision is weighed against the 
limited time she imagines she will have and what gives life meaning, on the other. After meeting a new life partner, she wants to spend much of her time with him.

But I still want to stop [working] I think, and calm down anyway. I want to have some joy left. A little freedom left. / ... / So my husband and I can travel a little, so we can have a nice time together. He's a widower and has been alone and I have been ... Well, so we can share life together.

The interviewee's story indicates how the driving forces that cause people to choose an extended working life can be weighed against the time they imagine they have left and other aspects of life that are considered meaningful (cf. Bengtsson \& Flisbäck 2021).

When tasks are considered in relation to life's meted - and therefore precious - time, the driving force is not just a matter of finding a contemporary context that allows one to receive recognition for the work and skills that have accumulated over a long period. The supervisory position also seems to have a particular meaning that extends beyond one's life, beyond the here and now. Transferring one's knowledge to a younger generation is seen as a particularly enriching task.

I've felt that I've transferred something from my years as a physician that they've welcomed. So that I've had the opportunity to hand over.

That the interviewee quoted above has been able to hand over knowledge accumulated over a long professional life to the younger colleagues also means that it will be easier to withdraw from the strong professional identity as physician. In addition, the older physicians point to the satisfaction of seeing that the program participants find the learning process relevant, grow in their profession and develop feelings of belonging and security.

Of course it's fun if the people you supervise feel they have benefited from it. / ... / Yes, that they have benefited, that they can move on. / ... / Only now that they go on and say they've felt secure in their role, and that it's gone well.

I've actually seen young people who the first times sat here with their arms on their chests, and did not want to talk at all. After some time someone begun to spoke. I remember one person in particular expressing 'I don't know what to say'. Then they've asked me to talk to them alone, and much has come to light about questions concerning their own role, their own ability. Then I've seen how the person in question has grown incredibly, it's very satisfying.

When one of the above quoted interviewees looks back on her professional life, she says that the best part has been the 'patient contacts' and doing good by 'perhaps having been able to help someone'. Here, we find similarities with the task of a supervisor: At best, the supervisor is a tool the other person can use to achieve a richer life. This interest in offering such a tool to others also seems to have been strengthened in a later life phase. Among the physicians, a particular desire seems to have emerged to pass on their knowledge to younger colleagues, to see how the protégé, after some time, develop into a good and clever doctor, and becomes an even better physician than the supervisor him- or herself. 
Then it's like this with age, that it's more fun, dealing with the younger people who follow you. And this, the joy of being able to hand over to clever people. / ... / It's a very great satisfaction to say that I've seen these people develop into good doctors.

$[\mathrm{T}] \mathrm{o}$ see how they grow and become full-fledged psychiatrists and become better than yourself.

The physicians' motivations to act as supervisors can be explained using Erikson's perspective on the seventh stage in the life cycle, a stage he suggested is caused by the crisis 'generativity vs. stagnation' (Erikson \& Erikson 1997). Thus, the physicians' interest in transferring their professional skills is a manifestation of a particular existential value that concerns a commitment to care about future generations.

Generativity refers to a developed concern for guiding the next generation. If generativity also implies that group mentoring offers a particular existential meaning, then it is important to understand the specific existential meaning involved. We have seen that what is meaningful is not only following the skill development of younger colleagues, that is, seeing how they manage and develop their knowledge, or becoming more involved in a new work context. In addition, the interviewees see how the activities they have devoted their life to is further developed, and will live on. This life-goes-on aspect may be of primary importance to anyone who is thinking about how the time they have left may be best put to use: A form of 'existential calm' may arise when one sees that the activities one finds important will continue. For one interviewee, the supervisory position is meaningful when she sees how the activities live on through other physicians. She paints a picture of herself in the future, being more vulnerable due to aging and therefore in need of more care, but nonetheless feeling secure because 'when I'm in need of healthcare, then maybe I'll meet one of them [the program participants].'

\section{Discussion and conclusion}

In this article, we contribute to the research field on work-related motives for postretirement work by analyzing underemphasized existential driving forces that become more prominent at a particular life phase. We have done this by studying a specific group of privileged professionals - older physicians - who do not in general have to continue to work for financial reasons.

First, we addressed how knowledge based on the physicians' professional experiences was recognized in the group mentoring practice. This experience of appreciation from peers have been stressed as essential to well-being and satisfaction in work and life overall (Sayer 2005). Moreover, receiving recognition for work reduces the probability of retirement, which was shown in a 12 European country study of employees aged 50 to 59 (Dal Bianco et al. 2015). Conversely, lack of recognition could have a negative effect on older employees' intentions to extend their work careers. For example, it had a significant effect on plans of early retirement among Danish employees 50 years or older (Thorsen et al. 2012), and low recognition increased the odds of exit from paid employment among English workers aged 50-69 (Carr et al. 2016). However, we argue that group mentoring does not only involve acknowledging professional experiences and skills. Because mentoring requires a wide range of skills, and as it focus on both 
professional and personal life, the older physicians also gain the trust of the younger physicians and recognition for who they are as human beings. In this context, it can be emphasized that the existential driving forces analyzed are not simply a matter of the rewards that derive from the tasks performed. As Hodson (2001, p. 3) pointed out, recognition for one's work is related to experiencing work tasks as meaningful in their own right: 'Life demands dignity, and meaningful work is essential for dignity'. Thus, there must be a match between what the work situation has to offer and what the individual perceives as a valuable life (Honneth 2003; Sayer 2005).

Following earlier research, to choose to accept the group mentoring task could be understood as a way to satisfy fundamental needs of socializing with others, as '[o]ne of the main discontinuities associated with full retirement is the lack of social interaction with others' (Van Solinge \& Henkens 2014, p. 1554). However, we argue that on the way into an existence as a retiree, mentoring offers the physicians a specific context. While this points back to the past - one's previous professional deeds founded in a strong professional identity - it also presents new challenges when exploring the profession's difficult and meaningful aspects in a new space with a new generation of colleagues. Thus, the specific context of group mentoring provides an opportunity for such an exchange between older and younger physicians. Moreover, if we relate this to work-related motives for continued work after retirement, this knowledge and experience exchange has been shown to be work organizations' most important task in engaging older employees in work, as seen in a German survey of active pensioners (Deller et al. 2009).

Moreover, the existential meaning that is awakened and developed in the mentoring practice should be interpreted in light of that the physicians are in a specific meaningseeking phase of life. If the work is to be worth the effort, it must have a specific existential significance. We have explained this in relation to aging and retirement as an existential imperative, in which the intrinsic aspects of work have become more important than before. Although the physicians have worked in a profession where they have constantly had to deal with life and death, they describe how personal losses have made the transience of life increasingly apparent. Thus, tasks are considered based on what the interviewees find meaningful in relation to the time they believe they have left (cf. Bengtsson \& Flisbäck 2021). Here, the mentor role seem to be of particular importance. In other words, the driving forces that cause people to choose an extended working life can be weighed against the time they imagine they have left and other aspects of life that are considered meaningful. In a similar way, a Finnish interview study of explanatory factors of employment exits near the retirement age, the decision to retire among male participants is influenced by the 'deaths of recently retired friends in similar work positions' (Kosonen et al. 2021, p. 80).

Finally, we have analyzed the specific meaning that group mentoring offers in the transfer of knowledge to a younger generation of professionals using Erikson's concept of generativity. The mentor role involves tasks with meaning that extends beyond the individual's life path, because it is a sign that the activity the individual has devoted his or her life to will continue after his or her death. Encounters with the program participants may even give hope that the performance of the activity will improve in the future. Thus, for the older physicians, handing over knowledge to the next generation is not 'just any job', but signifies that the life (one believes in) will go on. In policy discussions concerning an extended working life, similar existential meaning aspects tend to be ignored (Biggs 2014).

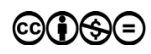


Understanding how existential driving forces are created and how they cause the individual to choose to continue working (or not) after retirement may be crucial to comprehending how we can take advantage of the resources the older part of the workforce have to offer. In the present case, it has been important to find new tasks, and a new place that contributes to development and new meetings but at the same time recognizes both professional and personal skills that they have developed over time. It is about finding an existential meaningful context in which the past is connected to the present, as well as pointing out that professional activities will continue beyond one's own life. Understanding and thematizing similar existential driving forces can thus be important knowledge to gain when preparing various policies meant to encourage an extended working life.

\section{Acknowledgement}

The research has been funded by the Swedish Research Council for Health, Working Life and Welfare (dnr 2013-2300) and the Region Västra Götaland.

\section{References}

Armstrong-Sassen, M. (2008). Organisational practices and the post-retirement employment experience of older workers, Human Resource Management Journal 18(1): 36-53. doi: https://doi.org/10.1111/j.1748-8583.2007.00057.

Bengtsson, M., Flisbäck, M. \& Lund, A. (2017). Farväl till arbetet. Sociologiska perspektiv på meningen med att gå i pension [Farewell to Labor. Sociological Perspectives on the Meaning of Retirement], Lund: Nordic Academic Press.

Bengtsson, M. \& Flisbäck, M. (2019). Möjligheter till meningsfullt arbete i ett förlängt yrkesliv: En studie av äldre läkares grupphandledning av utlandsutbildade kollegor [Opportunities for meaningful work in an extended professional life: A study of older physicians' group supervision of colleagues trained abroad], Arbetsliv i Omvandling 1: 1-61. https:// journals.lub.lu.se/aio/article/view/19661/18380.

Bengtsson, M. \& Flisbäck, M. (2021). Illuminating Existential Meaning: A New Approach in the Study of Retirement, Qualitative Sociology Review 17(1): 196-214. doi: http:// dx.doi.org/10.18778/1733-8077.17.1.12.

Berglund, T., Seldén, D. \& Halleröd, B. (2017). Factors Affecting Prolonged Working Life for the Older Workforce: the Swedish Case, Nordic Journal of Working Life Studies 7(1): 19-36. doi: https://doi.org/10.18291/njwls.v7i1.81396.

Biggs, S. (2014). The promise of a long life? Cultural adaptation to productive aging, spiritual empathy, and a sustainable future, Journal of Religion, Spirituality \& Aging 26: 96-108. doi: https://doi.org/10.1080/15528030.2013.855964.

Bolton, S. C. (2007). Dignity in and at work: why it matters. In S. C. Bolton (ed.), Dimensions of Dignity at Work (pp. 3-16), Oxford: Butterworth-Heinemann.

Brante, T., Johnsson, E., Olofsson, G. \& Svensson, L. (2015). Professionerna i kunskapssamhället [The professions in the knowledge society], Stockholm: Liber.

Calo, T. J. (2005). The Generativity Track: A Transitional Approach to Retirement, Public Personnel Management 34(4): 301-312. doi: https://doi.org/10.1177/009102600503400402.

Carr, E., Hagger-Johnson, G., Head, J., Shelton, N., Stafford, M., Stansfeld, S. \& Zaninotto, P. (2016). Working conditions as predictors of retirement intentions and exit from paid 
employment: a 10-year follow-up of the English longitudinal study of ageing, European Journal of Ageing 13(1): 39-48. doi: https://doi.org/10.1007/s10433-015-0357-9.

Charmaz, K. (2014). Constructing Grounded Theory, London: Sage.

Chen, Kuan-Lun M. \& Gardiner, E. (2019). Supporting older workers to work: a systematic review, Personnel Review 48(5): 1318-1335. doi: https://doi.org/10.1108/PR-11-2018-0455.

Dal Bianco, C., Trevisan, E. \& Weber, G. (2015). 'I want to break free'. The role of working conditions on retirement expectations and decisions, European Journal of Ageing 12(1): 17-28. doi: https://doi.org/10.1007/s10433-014-0326-8.

Deller, J., Liedtke, P. M. \& Maxin, L. M. (2009). Old-Age Security and Silver Workers: An Empirical Survey Identifies Challenges for Companies, Insurers and Society, The Geneva Papers 34: 137-157. doi: https://doi.org/10.1057/gpp.2008.44.

Doerwald, F., Scheibe, S. \& Van Yperen, N. W. (2015). Role of Age in Workplace Mentoring. In N. A. Pachana (ed.), Encyclopedia of Geropsychology (pp. 1-8), Singapore: Springer Science.

Erikson, E. H. (1950). Childhood and society, New York: W. W. Norton \& Co.

Erikson, E. H., Erikson, J. M. \& Kivnick, H. Q. (1986). Vital Involvement in Old Age. The Experience of Old Age in Our Time, New York/London: W. W. Norton \& Co.

Erikson, E. H., \& Erikson, J. M. (1997). The life cycle completed. Extended version, New York/London: W. W. Norton \& Co.

Eurostat (2018). Smarter, greener, more inclusive? Indicators to support the Europe 2020 strategy, Luxembourg: Publications Office of the European Union.

Heidegger, M. (1927/2013). Vara och tid [Being and time], Göteborg: Daidalos.

Hodson, R. (2001). Dignity at work, Cambridge: Cambridge University Press.

Holton, J. (2007). The Coding Process and Its Challenges. In A. Bryant \& K. Charmaz (eds) The SAGE Handbook of Grounded Theory (pp. 265-290), London: Sage.

Honneth, A. (2003). Erkännande. Praktisk-filosofiska studier [Recognition. Practicalphilosophical studies], Göteborg: Daidalos.

Jackson, M. D. (2005). Existential anthropology, New York: Berghahn.

Jackson, M. D. (2011). Life Within Limits. Well-being in a World of Want, Durham and London: Duke University Press.

Jonsson, H. (2000). Anticipating, experiencing and valuing the transition from worker to retiree, Stockholm: Karolinska Institutet.

Jonsson, R., Lindegård, A., Björk, L. \& Nilsson, K. (2020). Organizational Hindrances to the Retention of Older Healthcare Workers, Nordic Journal of Working Life Studies 10(1): 41-58. doi: https://doi.org/10.18291/njwls.v10i1.118679.

Kadefors, R. \& Johansson Hanse, J. (2012). Employers' Attitudes Toward Older Workers and Obstacles and Opportunities for the Older Unemployed to Reenter Working Life, Nordic Journal of Working Life Studies 2(3): 29-47. doi: https://doi.org/10.19154/njwls. v2i3.2362.

Kadefors, R., Schaller, J., Thång, P.-O. \& Pestat, E. (2016). Attitudes Among Male and Female University Professors, and other Categories of University Employees, to Working up to and Beyond Normal Retirement Age, Nordic Journal of Working Life Studies 6(1): 133-146. doi: https://doi.org/10.19154/njwls.v6i1.4913.

Kadefors, R., Nilsson, K., Rylander, L., Östergren, P.-O. \& Albin, M. (2018). Occupation, gender and work-life exits: a Swedish population study, Ageing \& Society 38: 1332-1349. doi: https://doi.org/10.1017/S0144686X17000083.

Kooij, D. T., de Lange, A., Jansen, P. \& Dikkers, J. (2008). Older workers' motivation to continue to work: five meanings of age, Journal of Managerial Psychology 23(4): 364-394. doi: https://doi.org/10.1108/02683940810869015.

Kooij, D. T., de Lange, A. H., Jansen, P. G., Kanfer, R. \& Dikkers, J. S. (2011). Age and work-related motives: Results of a meta-analysis, Journal of Organizational Behaviour 32(2): 197-225. doi: https://doi.org/10.1002/job.665. 
Kosonen, H., Keskinen, K., Nikander, P. \& Lumme-Sandt, K. (2021). Employment Exits Near Retirement Age: An Agency-analysis, Nordic Journal of Working Life Studies 11(1): 63-83. doi: https://doi.org/10.18291/njwls.122227.

Lindgren, Å., Bååthe, F. \& Dellve, L. (2013). Why risk professional fulfilment: a grounded theory of physician engagement in healthcare development, The International Journal of Health Planning and Management 28: e138-e157. doi: https://doi.org/10.1002/hpm.2142.

Mor-Barak, M. E. (1995). The Meaning of Work for Older Adults Seeking Employment: The Generativity Factor, The International Journal of Aging and Human Development 41(4): 325-344. doi: https://doi.org/10.2190/VGTG-EPK6-Q4BH-Q67Q.

Mykletun, R. \& Furunes, T. (2011). The Ageing Workforce Management Program in Vattenfall AB Nordic. In R. Ennals \& R. Salomon (eds.), Older Workers in a Sustainable Society (pp. 93-105), Bern: Peter Lang.

Nilsson, K., Rignell Hydbom, A. \& Rylander, L. (2011). Factors influencing the decision to extend working life or retire, Scandinavian Journal of Work, Environment \& Health 37(6): 473-480. doi: https://doi.org/10.5271/sjweh.3181.

OECD/European Observatory on Health Systems and Policies (2017). Sverige: Landprofil hälsa 2017 [Sweden: Country profile health 2017], State of Health in the EU. OECD Publishing, Paris/European Observatory on Health Systems and Policies, Brussels.

Sayer, A. (2005). The Moral Significance of Class, Cambridge: Cambridge University Press.

Solem, P. E., Syse, A., Furunes, T., Mykletun, R. J., de lange, A. H., Schaufeli, W. B., \& Ilmarinen, J. (2016). To leave or not to leave: Retirement intentions and retirement behaviour, Ageing \& Society 36(2): 259-281. doi: http://dx.doi.org/10.1017/ S0144686X14001135.

Thorsen, S., Rugulies, R., Løngaard, K., Borg, V., Thielen, K. \& Bjorner, Bue J. (2012). The association between psychosocial work environment, attitudes towards older workers (ageism) and planned retirement, International Archives of Occupational and Environment Health 85(4): 437-445. doi: https://doi.org/10.1007/s00420-011-0689-5.

von Below, B., Haffling, A. C., Brorsson, A., Mattsson, B. \& Wahlqvist, M. (2015). Student-centred GP ambassadors: Perceptions of experienced clinical tutors in general practice undergraduate training, Scandinavian Journal of Primary Health Care 33(2): 142-149. doi: https://doi.org/10.3109/02813432.2015.1041826.

von Below, B., Rödjer, S., Mattsson, B., Hange, D. \& Wahlqvist, M. (2018). What factors motivate junior doctors to engage as clinical tutors? A qualitative study, International Journal of Medical Education 9: 151-157. doi: https://doi.org/10.5116/ijme.5b07.d108.

Van Solinge, H. \& Henkens, K. (2014). Work-related factors as predictors in the retirement decision-making process of older workers in the Netherlands, Ageing \& Society 34(9): 1551-1574. doi: https://doi.org/10.1017/S0144686X13000330.

\section{Notes}

${ }^{1}$ The medical profession is characterized by beneficial working and living conditions, for example, a high salary, good career opportunities and intrinsic task rewards (Brante et al. 2015; Lindgren et al. 2013).

${ }^{2}$ Between 2000 and 2015, the number of foreign-trained doctors in Swedish healthcare increased threefold (OECD/European Observatory on Health Systems and Policies 2017). In this way, the training program for healthcare personnel is a matter of organizational integration management. 